\title{
The effect of cytokine leukemia-inhibitory factor (LIF) and interleukin-11 (IL-11) gene expression on the primary infertility related to polycystic ovary syndrome, Tubal factor, and Unexplained infertility in Turkish women
}

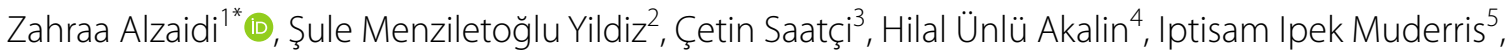
Buşra Aynekin ${ }^{3}$, Izem Olcay Şahin ${ }^{3}$ and Munis Dündar ${ }^{3}$

\begin{abstract}
Background: Successful implantation of blastocysts is indeed an important path in mammalian reproduction that is governed by a complicated web of cytokines interactions. Leukemia inhibitory factor (LIF) and interleukin-11 (IL-11) part of the interleukin (IL)-6 groups are cytokines that are needed for effective implantation and prevent infertility symptoms. This study aimed to determine the expression level (LIF, IL-11) genes in patients with primary infertility related to polycystic ovary syndrome (PCOS), tubal factor infertility (TFI), and unexplained infertility (UI).

Results: In this study, 75 infertility women and 40 controls were involved. The expressions of LIF and IL-11 genes were evaluated by quantitative real-time polymerase chain reaction qRT-PCR Light Cycler in patients and healthy controls. PCOS, TFI, and UI groups showed promising results regarding LIF gene, which appeared at very small levels compared to the control $(p<0.0001)$. Regarding $\mathrm{IL}-11$, the two groups TFI and UI were significantly linked to the lower level of gene expression, while the PCOS group has no significant difference when it is compared to the control group $(p<0.0001,<0.05,0.19)$, respectively.

Conclusion: The current findings show that low levels of LIF and IL-11 gene expression are linked to various primary infertility conditions, including PCOS, tubal factor, and unexplained infertility since they play a fundamental role in embryo implantation.
\end{abstract}

Keywords: Leukemia inhibitory factor (LIF), PCOS, Interleukin-11 (IL-11), Primary infertility, Tubal factor infertility (TFI), Unexplained infertility (UI)

\section{Background}

Reproduction is a prerequisite for maintaining the existence of any species. In humans, fertility refers to a woman's capacity to become pregnant [1]. Infertility is

\footnotetext{
*Correspondence: biotech.zahraa@gmail.com

1 Department of Biotechnology, Faculty of Applied Science, Cukurova

University, Adana, Turkey

Full list of author information is available at the end of the article
}

a prevalent human condition, affects millions of reproductive-age individuals worldwide, and it impacts their families and communities [2]. According to the Turkey Demographic and Health Survey, the prevalence of infertility in women in Turkey is significantly between 10 and $15 \%$ [3]. One of the main causes of hormone dysregulation is polycystic ovary syndrome (PCOS), a cluster of clinical symptoms found within a phenotypically heterogeneous group of women linked to ovarian dysfunction 
[4]. Another main frequent reason for primary fertility problems is tubal factor infertility (TFI), related to blockages, destruction, tissue damage, congenital abnormalities, as well as other triggers that hinder a fertilized or unfertilized ova from descending into the uterus via the fallopian tubes and preventing a successful pregnancy [5]. Correspondingly, fertility aberrations are likely to appear in unexplained infertility (UI) but are undetectable with the existing technologies. Aberrations in endocrinological equilibrium and the immune system as well as the defect of the genetic and reproductive physiology have all been suggested as possible explanations of unexplained infertility [6]. However, defects in endometrial receptivity may be one cause of fertility issues in these women, in which embryos cannot implant in the uterus if the endometrium is damaged [7]. The implant process or implantation is the action through which the blastocyst connects to the underlying endometrial layer and eventually penetrates, which is a dynamic and flexible process. It is essential to create an efficient 'interference' between maternal and embryonic tissues that entails many endocrines, paracrine, and autocrine influences [8]. A comprehensive framework of molecules is activated at the maternal-fetal interacting together under the control of ovarian hormones, which play a critical role in facilitating the events [9]. LIF (leukemia inhibitory factor) is one of the interleukin-6 (IL-6) families of cytokines; IL- 6 and IL-11 are also part of the group. LIF is related to the subsequent activities throughout implantation: the receptive condition of the endometrium, the connection between the embryo and the endometrium, stromal decidualization, trophoblast invasion, blastocyst development and growth, and uterine leukocyte infiltration, according to evidence [10]. Interleukin-11 (IL-11), the second member of interleukin-6 (IL-6), is thought to be essential for decidualization in the endometrium, which promotes blastocyst adhesion and implantation by acting primarily on uterine luminal epithelium and blastocyst [11]. Given this, this work aimed to study the predictable pathophysiology of the cytokine, leukemia inhibitory factor (LIF), and interleukin-11 (IL-11), in women suffering from primary infertility related to polycystic ovary syndrome (PCOS), tubal factor infertility (TFI), and unexplained infertility (UI).

\section{Methods}

\section{Study design}

This prospective case study was conducted in ERCIYES University hospitals, Department of Medical Genetics, Kayseri, Turkey, between June 2019 and June 2021. A total of 75 patient women between 21 and 45 years of age had been examined by a gynecologist, and they were suffering from 2 to 7 years of primary infertility divided into three categories depending on the related case polycystic ovary syndrome (PCOS), tubal factor infertility (TFI), and unexplained infertility (UI). 25 women free from signs and symptoms of PCOS, tubal factor dependent on the medical criteria, clinically healthy, had a regular menstrual cycle, exhibited normal ovulation and without any infertility signs have involved as a control group. To complete the study, all patients and control groups were not taking any medication or fertility drugs known to affect ovulation for at least 3 months before the study, and they are having irregular periods, no periods, or abnormal bleeding.

\section{Body mass index and waist circumference}

Body mass index (BMI) testing is recommended by the World Health Organization (WHO) to determine overweight and obesity. Furthermore, BMI determines women's fertility in a significant direction, reduced female reproduction is linked to higher and lower levels of BMI [12]. BMI value, unhealthily thin weight $(<18)$, regular weight (18-24.9), overweight (25-29.9), obesity (30$39.9)$, and severe obesity $(>40)$ were classified by utilizing equation $\mathrm{BMI}=$ weight $(\mathrm{kg}) /$ height $^{2}(\mathrm{~m})$ [13]. When the subject was standing up, the waist circumference was calculated at the closest part of the torso width-wise, in general directly just over the abdominal button, and the standard value $88 \mathrm{~cm}$ in females [13].

\section{Samples of blood}

Peripheral blood collections $(10 \mathrm{~mL})$ were taken from the patient volunteer who signed a written informed consent form in ERCIYES University hospitals, Kayseri, Turkey. Each blood sample was saved in EDTA tubes and stored at the refrigerator temperature between 2 and $8{ }^{\circ} \mathrm{C}$ for molecular studies.

\section{RNA isolation and PCR amplification}

Total RNA was extracted using TRIZOL reagent (Thermo Fisher Scientific, USA). Trizol ensures RNA integrity while lysing cells and dissolving cell components during homogenization or lysis. Total RNA $(1 \mu \mathrm{g})$ was reverse transcribed using the EvoScript Universal cDNA Master Strand Kit according to the manufacturer's instructions. The mRNA expression level of LIF and IL-11 genes was examined by quantitative real-time qRT-PCR LightCycler 480 kit from Roche. The temperature and times programs for expression in LightCycler 480 II software are shown in Additional file 1: Table 1. A pair of specific primers was provided by Light Cycler 480 Probes Master (Roche) for each marker (LIF, IL-11) shown in Additional file 2: Table 2. Gene expression levels were normalized to beta-actin (ACTB). 
Table 1 Physical parameters of normal controls and infertility subjects (women)

\begin{tabular}{|c|c|c|c|c|c|}
\hline Parameters & $P \operatorname{COS}(n=25)$ & Tubal factor $(n=25)$ & $\begin{array}{l}\text { Unexplained infertility } \\
(n=25)\end{array}$ & Control $(n=25)$ & $p$ value \\
\hline Age (years) & $32.87 \pm 7.41$ & $33.98 \pm 8.11$ & $32.80 \pm 7.10$ & $28.45 \pm 6.14$ & ${ }^{*}<0.05$ \\
\hline $\mathrm{BMI}\left(\mathrm{kg} / \mathrm{m}^{2}\right)$ & $32.73 \pm 2.88$ & $31.73 \pm 2.36$ & $31.88 \pm 2.99$ & $20.73 \pm 2.36$ & $*<0.05$ \\
\hline Waist/hip ratio (WHR) & $0.82 \pm 0.06$ & $0.80 \pm 0.04$ & $0.81 \pm 0.06$ & $0.80 \pm 0.07$ & 0.25 \\
\hline Infertility duration (years) & $3.78 \pm 1.22$ & $2.80 \pm 1.01$ & $4.09 \pm 2.11$ & - & - \\
\hline
\end{tabular}

${ }^{*} p<0.05=$ Significant

\section{Statistical analysis}

cDNA synthesis and qPCR results were independently replicated twice. Statistical significance levels of mRNA expressions were analyzed using the GraphPad Prism test. ANOVA repeated measures were used to compare the mean of physiological parameters between the patients' groups. Statistical significance was determined by $p \leq 0.05$ values.

\section{Results}

The findings of this current study indicated a considerable relationship $(p<0.05)$ in the physical and physiological measurements between infertile and control groups shown in Table 1. Age and BMI were significantly higher $(p<0.05)$ in the infertile patients compared with the control group. There was no meaningful association between the remaining diagnostic indicators regarding waist/hip ratio $(p 0.25)$ and infertility duration $(p 0.29)$. The age limit of the patient groups was $32-45$ years; the mean value was $32.87 \pm 7.41,33.98 \pm 8.11,32.80 \pm 7.10$ for POCS, tubal factor, unexplained infertility groups sequentially. The age limit of the control group was $23-43$ years, and the average age was $28.45 \pm 6.14$ with $p$ value $<0.05$ as in Table 1 .

In terms of genetic analysis, the research data revealed that LIF gene expression level in the infertile patient groups was considerably lower than that in the control group $0.230 \pm 0.029,0.190 \pm 0.022,0.138 \pm 0.021$ for POCS, tubal factor, unexplained infertility groups sequentially and mean average $(0.230 \pm 0.043)$ for control healthy group, demonstrating a highly significant correlation with $p$ value $<0.0001$ and $<0.001$ (Table 2, Fig. 1).

Consecutively the expression gene level of IL-11 was remarkably higher in the healthy control group $0.223 \pm 0.04$ than in the unexplained infertility group $0.190 \pm 0.09$ with a significant result $(p$ value $<0.05)$, the second group (tubal factor) also showed a highly notable correlation ( $p$ value $<0.0001)$ compared to the control group $(0.167 \pm 0.026,0.223 \pm 0.04)$ sequentially. There was no significant correlation concerning PCOS group $0.239 \pm 0.08$ ( $p$ value 0.19 ) (Table 3 , Fig. 1 ).
Table 2 Mean, standard deviation, and $p$ values of study groups for LIF gene

\begin{tabular}{llll}
\hline Study group $(\mathbf{n}=\mathbf{7 5})$ & $\begin{array}{l}\text { Average and } \\
\text { standard } \\
\text { deviation }\end{array}$ & Control & $\boldsymbol{p}$ value \\
\hline PCOS & $0.230 \pm 0.029$ & $0.230 \pm 0.043$ & $*<0.0001$ \\
Tubal factor & $0.190 \pm 0.022$ & $*<0.001$ \\
Unexplained (no reason) & $0.138 \pm 0.021$ & & $*<0.001$ \\
\hline${ }^{*} p<0.05=$ Significant & &
\end{tabular}

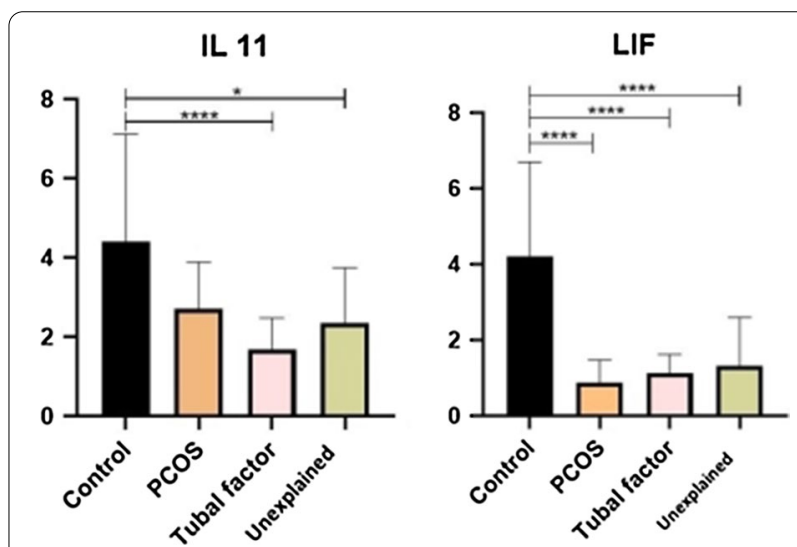

Fig. 1 Mean, standard deviation, and $p$ values of study groups for LIF and IL-11 gene

Table 3 Mean, standard deviation, and $p$ values of study groups for IL-11 gene

\begin{tabular}{lllc}
\hline Study group $(\mathbf{n = 7 5 )})$ & $\begin{array}{l}\text { Average and } \\
\text { standard } \\
\text { deviation }\end{array}$ & Control $(\mathbf{n = 2 5 )}$ & $\boldsymbol{p}$ value \\
\hline PCOS & $0.239 \pm 0.08$ & $0.223 \pm 0.04$ & 0.19 \\
Tubal factor & $0.167 \pm 0.026$ & & $*<0.0001$ \\
$\begin{array}{l}\text { Unexplained (no } \\
\text { reason) }\end{array}$ & $0.190 \pm 0.09$ & & $*<0.05$ \\
${ }^{*} p<0.05=$ Significant & & & \\
\hline
\end{tabular}




\section{Discussion}

The findings of this research showed that increased BMI had a discernible effect with infertility patient groups (PCOS, tubal factor, and unexplained infertility), indicating that a high level of BMI affects the reproductive functions through dysregulation of several pathways, which includes androgen receptors, leptin, or even pro-inflammatory cytokines like interleukins (IL-1), tumor necrosis factor (TNF), cytokine leukemia-inhibitory factor (LIF), interleukin-11 (IL-11), insulin-like growth factor (IGF)-I and II, as well as transforming growth factor (TGF)-I and II [14].

In this clinical study, the relationship of infertility with cytokines gene was examined by assessing the mRNA expressions of leukemia-inhibitory factor (LIF) and interleukin-11 (IL-11), an important factor in the embryo implantation process in women who had primary infertility related to PCOS, tubal factor and unexplained infertility.

The results revealed that LIF gene expression level in PCOS patients was considerably lower than that in the control group $(p<0.0001)$; these outcomes were equivalent to a study by Hussein et al. [15] which revealed that any increase or reduction in LIF gene expression levels is significantly useful in predicting reproductive outcomes in infertile women with PCOS than for non-PCOS females.

This gene is supposed to be an endometrial receptivity indicator, and its mutational expressions may aid in the identification of females who have experienced implantation failure [16].

Additionally, in comparison with the control fertile healthy group, LIF expression level was significantly lower in the second group who are suffering from infertility related to tubal factor $(p<0.001)$; this result shows that the occurrence of the blockage in the fallopian tubes may lead to a decrease in the LIF gene expression in the luminal epithelium of the fallopian tube, the central place for the process of the pre-implantation embryo [17]. According to Li et al. [18] research, the intensity of LIF gene expression in the embryonic culture medium could be used as a non-invasive supplementary biomarker for clinical pregnancy prediction in infertile females diagnosed with tubal problems, which are undergoing a single blastocyst transfer process.

The LIF gene expression also has been detected in a manner of significantly low level in women with unexplained infertility. Otherwise, the fertile control group showed higher levels of LIF expression $(p<0.001)$. This result suggests that infertile women's LIF gene expression may be dysregulated in both the proliferative and secretory phases, leading to a defect in the endometrial LIF activity which can be the main cause of unexplained infertility and recurrent implantation failures. The findings were identical to those of the research of Steck et al. [19].

Furthermore, along with interleukin-11 (IL-11) gene expression, there was no statistical difference between infertility PCOS females and the control fertile group, while this correlation was discovered and it is linked to adipocyte proliferation by Zhuang et al. [20] study. This discrepancy may be related to different inclusion criteria and the impossibility to rule out all factors that influence IL-11 gene expression levels.

However, the highly significant different results in the levels of IL-11 gene expression between the control group and the second patient group (infertility females with tubal factor) reinforce the findings of Cakmak et al. [21] in their research, which reported that IL-11 secretion is destructed by tubal epithelial cells in response to Chlamydia trachomatis infection, the main cause of tubal factor infertility, which causes extensive destruction of the ciliated cells. It confirms the direct role of IL-11 in the pathogenicity of tubal factor infertility women.

Patients with the unexplained infertility group also recorded a significant correlation concerning the level of the IL-11 gene $(p<0.05)$. This result hypothesized that IL-11 may be dysregulated in the glandular epithelium, which leads to preventing the facilitation of its secretory and prevents the attachment or adhesion of the blastocyst on the endometrial uterine epithelium, leading to the formation main cause for unexplained infertility [22].

\section{Conclusions}

Our findings show that low levels of LIF and IL-11 gene expression are linked to a variety of primary infertility conditions, including PCOS, tubal factor, and unexplained infertility, since they play a fundamental role in embryo implantation. We note that this was merely a preliminary study so that more LIF and IL-11 gene low expression infertile women are required for some further research. Investigation of the probability of mutations within IL-11 and LIF genes and their relation to infertility are recommended for more confirming results.

\footnotetext{
Abbreviations

ACTB: Beta-actin; BMI: Body mass index; EDTA: Ethylenediamine tetraacetic acid; IGF-I: Insulin-like growth factor; IL-6, 11: Interleukin-6, 11; LIF: Leukemia inhibitory factor; PCOS: Polycystic ovary syndrome; qRT-PCR: Quantitative realtime polymerase chine reaction; TFI: Tubal factor infertility; TGF-l: Transforming growth factor; TNF: Tumor necrosis factor; UI: Unexplained infertility; WHO: World Health Organization.
} 


\section{Supplementary Information}

The online version contains supplementary material available at https://doi. org/10.1186/s43042-021-00201-9.

Additional file 1: Supplementary Table 1. Temperature and times programs for expression in LightCycler 480 II software.

Additional file 2: Supplementary Table 2. Primer Sequences.

\section{Acknowledgements}

The authors extend their gratitude to all of the contributors.

\section{Authors' contributions}

$Z A$, ŞY, ÇS, HA, IM, and MD contributed to infertility diagnosis, genetic analysis section and interpreting the patient data, regarding hormonal and blood test as well as the major contribution in writing the manuscript by ZA, BA, and Iş. All authors read and approved the final manuscript.

\section{Funding}

The authors have not declared a specific grant for this research from any funding agency in the public, commercial, or not-for-profit sectors.

\section{Availability of data and materials}

Data are available upon request.

\section{Declarations}

\section{Ethics approval and consent to participate}

The study was approved by Erciyes University Hospitals, Medical Genetics Department, Kayseri, Turkey. Reference No. (ERC-305), all the patients in the study had been signed for a written consent before the procedure.

\section{Consent for publication}

Not Applicable.

\section{Competing interests}

The authors did not report any conflict of interest.

\section{Author details}

'Department of Biotechnology, Faculty of Applied Science, Cukurova University, Adana, Turkey. ${ }^{2}$ The Blood Center of Balcali Hospital, Faculty of Medicine, Cukurova University, Adana, Turkey. ${ }^{3}$ Department of Medical Genetics, Faculty of Medicine, Erciyes University, Kayseri, Turkey. ${ }^{4}$ Department of Medical Genetics, Faculty of Medicine, Kırşehir Ahievran University, Kırşehir, Turkey. ${ }^{5}$ Department of Obstetrics and Gynecology, Erciyes University Medicine Faculty, Kayseri, Turkey.

Received: 9 July 2021 Accepted: 3 October 2021 Published online: 07 December 2021

\section{References}

1. Chua SJ, Danhof NA, Mochtar MH et al (2020) Age-related natural fertility outcomes in women over 35 years: a systematic review and individual participant data meta-analysis. Hum Reprod 35:1808-1820

2. Female Infertility_StatPearls_NCBI Bookshelf. https://www.ncbi.nlm. nih.gov/books/NBK556033/. Accessed 18 Jun 2021

3. Soyiç Y, Süzer Özkan F (2020) Infertilitede Kullanılan Geleneksel ve Tamamlayıcı Tıp Uygulamaları. Ordu Üniv Hemşire Çalış Derg 2020:169_ 175. https://doi.org/10.38108/ouhcd.747957
4. Hiam D, Moreno-Asso A, Teede HJ et al (2019) The genetics of polycystic ovary syndrome: an overview of candidate gene systematic reviews and genome-wide association studies. J Clin Med 8:1606. https://doi.org/10. 3390/jcm8101606

5. Ljubin-Sternak S, Meštrović T (2014) Chlamydia trachomatis and genital mycoplasmas: pathogens with an impact on human reproductive health. J Pathog 2014:1-15. https://doi.org/10.1155/2014/183167

6. Barbieri RL (2019) Female Infertility. In: Yen \& Jaffe's reproductive endocrinology: physiology, pathophysiology, and clinical management, 8th edn. Elsevier, Amsterdam, pp 556-581.e7

7. Messaoudi S, EL Kasmi I, Bourdiec A et al (2019) 15 years of transcriptomic analysis on endometrial receptivity: what have we learnt? Fertil Res Pract. https://doi.org/10.1186/s40738-019-0059-7

8. Kim S-M, Kim J-S (2017) A review of mechanisms of implantation. Dev Reprod 21:351-359. https://doi.org/10.12717/dr.2017.21.4.351

9. Comiskey M, Warner CM, Schust DJ (2013) MHC molecules of the preimplantation embryo and trophoblast. Madame Curie Biosci 2000-2013, 7. https://www.ncbi.nlm.nih.gov/books/NBK6277/

10. Yoshinaga K (2018) A historical review of blastocyst implantation research. Biol Reprod 99:175-195

11. Wang $\mathrm{H}$, Zhang S, Lin $\mathrm{H}$ et al (2013) Physiological and molecular determinants of embryo implantation. Mol Aspects Med 34:939-980

12. Silvestris E, de Pergola G, Rosania R, Loverro G (2018) Obesity as disruptor of the female fertility. Reprod Biol Endocrinol 16:1-13

13. Murguía-Romero M, Jiménez-Flores R, Méndez-Cruz AR, Villalobos-Molina $\mathrm{R}$ (2012) Improving the body mass index (BMI) formula with heuristic search. In: Proceedings of special session-revised papers, 11th Mexican international conference on artificial intelligence 2012: advances in artificial intelligence and applications, MICAI 2012. pp 100-104

14. Dağ ZÖ, Dilbaz B (2015) Impact of obesity on infertility in women. J Turk Ger Gynecol Assoc 16:111-117

15. Hussein ZF (2018) Role of leukemia inhibitory factor (LIF) gene variation on implantation rate following IVF program in PCOS and non-PCOS women. Iraqi J Biotechnol 17:57-67

16. Aghajanova L (2004) Leukemia inhibitory factor and human embryo implantation. In: Annals of the New York academy of sciences. New York Academy of Sciences, pp 176-183

17. Shaw JLV, Dey SK, Critchley HOD, Horne AW (2010) Current knowledge of the aetiology of human tubal ectopic pregnancy. Hum Reprod Update $16: 432-444$

18. Li Z (2020) LIF level is a predictive marker for clinical pregnancy following IVF-ET of patients with fallopian tube obstruction. https://doi.org/10. 21203/RS.2.24226/V2

19. Steck T, Giess R, Suetterlin MW et al (2004) Leukaemia inhibitory factor (LIF) gene mutations in women with unexplained infertility and recurrent failure of implantation after IVF and embryo transfer. Eur J Obstet Gynecol Reprod Biol 112:69-73. https://doi.org/10.1016/S0301-2115(03)00315-4

20. Zhuang Z, Pan X, Zhao K et al (2019) The effect of Interleukin-6 (IL-6), Interleukin-11 (IL-11), signal transducer and activator of transcription 3 (STAT3), and AKT signaling on adipocyte proliferation in a rat model of polycystic ovary syndrome. Med Sci Monit 25:7218-7227. https://doi.org/ 10.12659/MSM.916385

21. Cakmak H, Taylor HS (2011) Implantation failure: molecular mechanisms and clinical treatment. Hum Reprod Update 17:242-253

22. Dimitriadis E, Menkhorst E, Salamonsen LA, Paiva P (2010) Review: LIF and IL-11 in trophoblast-endometrial interactions during the establishment of pregnancy. Placenta. https://doi.org/10.1016/j.placenta.2009.12.027

\section{Publisher's Note}

Springer Nature remains neutral with regard to jurisdictional claims in published maps and institutional affiliations. 